\section{(6) OPEN ACCESS}

\title{
Injury surveillance in the World Football Tournaments 1998-2012
}

\author{
Astrid Junge, Jiri Dvorak
}

FIFA Medical Assessment and Research Centre (F-MARC), Schulthess Clinic, Zurich, Switzerland

\section{Correspondence to}

Dr Astrid Junge, FIFA Medical Assessment and Research Centre (F-MARC), Schulthess Klinik, Lengghalde 2, Zurich $\mathrm{CH}-8008$, Switzerland; Astrid. Junge@F-MARC.com

Accepted 29 March 2013 Published Online First 30 April 2012

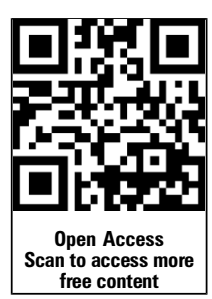

To cite: Junge A, Dvorak J. Br J Sports Med 2013;47:782-788.

\section{ABSTRACT}

Background International sports bodies should protect the health of their athletes, and injury surveillance is an important pre-requisite for injury prevention. The Fédération International de Football Association (FIFA) has systematically surveyed all football injuries in their tournaments since 1998.

Aims Analysis of the incidence, characteristics and changes of football injury during international top-level tournaments 1998-2012.

Methods All newly incurred football injuries during the FIFA tournaments and the Olympic Games were reported by the team physicians on a standardised injury report form after each match. The average response rate was $92 \%$.

Results A total of 3944 injuries were reported from 1546 matches, equivalent to 2.6 injuries per match. The majority of injuries ( $80 \%$ ) was caused by contact with another player, compared with $47 \%$ of contact injuries by foul play. The most frequently injured body parts were the ankle $(19 \%)$, lower leg (16\%) and head/neck (15\%). Contusions (55\%) were the most common type of injury, followed by sprains (17\%) and strains (10\%). On average, 1.1 injuries per match were expected to result in absence from a match or training. The incidence of time-loss injuries was highest in the FIFA World Cups and lowest in the FIFA U17 Women's World Cups. The injury rates in the various types of FIFA World Cups had different trends over the past 14 years.

Conclusions Changes in the incidence of injuries in toplevel tournaments might be influenced by the playing style, refereeing, extent and intensity of match play. Strict application of the Laws of the Games is an important means of injury prevention.

\section{INTRODUCTION}

The Fédération International de Football Association (FIFA) started to systematically document all injuries of players in the 1998 FIFA World Cup. ${ }^{1}$ Football injuries in 51 FIFA tournaments (see table 1) and in four Olympic Games have been surveyed until 2012.

Other sport federations (eg, International Handball Federation (IHF), International Association of Athletics Federations (IAAF), Fédération Internationale de Natation (FINA), International Rugby Board (IRB), Fédération Internationale de Volleyball (FIVB)), ${ }^{2-15}$ football confederations (Union of European Football Associations (UEFA), Asian Football Confederation (AFC)), ${ }^{16-18}$ and the International Olympic Committee (IOC) ${ }^{711} 12$ followed FIFA's model; however, no report on such a number of tournaments or over a period of 14 years has been published previously.

Injury surveillance should be the first step in injury prevention. ${ }^{19}$ Furthermore, long-term injury surveillance enables changes to be monitored over time, and in relating them to the development of the game, modifications in playing style, rule changes or introduction of new equipment or playing surfaces.

The aim of this study was to summarise the frequency, characteristics and circumstances of football injury during the FIFA tournaments and the Olympic Games from 1998 to 2012, and to analyse trends in injury incidence in different types of tournaments during this period.

\section{METHODS}

The injury-reporting system was developed for the documentation of football injuries during tournaments and has been implemented routinely in all the FIFA competitions since $1998,{ }^{120-24}$ as well as in the football tournaments of the Olympic Games since 2000.7 1112

The injury definition and data collection procedures are in accordance with the respective consensus statement. ${ }^{25}$ During a pretournament instructional meeting, the physicians of all the participating teams were asked to report all injuries that had occurred during the matches, and they were informed on how to fill in the injury report forms. The injury report form comprised a single page on which all injuries sustained during a given match or, when applicable, the non-occurrence of injury should be described in tabular form. ${ }^{1}$ An injury was defined as any physical complaint (including concussion) incurred during a match that received medical attention from the team physician regardless of the consequences with respect to absence from the match or training. ${ }^{1}$

For all injuries, the following information was required to be documented: time of injury (minute in the match), injured body part and type of injury, circumstances (non-contact, contact and foul play) and consequences of injury (referee's sanction, treatment, and time-loss in training or match). In the first tournaments (1998-2000), an earlier version of the injury report form was used, which did not include the physician's judgement about foul play and the consequences of the injury. For the Confederations Cup 2009 and the 2010 FIFA World Cup, the report form was modified to also include illnesses ${ }^{20}$; in these two tournaments and in the Olympic Games 2008, the circumstances of injury were recorded in one category instead of two. ${ }^{11} 20$

All the FIFA World Cups, the FIFA Confederations Cups, and the football tournaments of the Olympic Games from 1998 to 2012 were included in the present study (see table 1). The FIFA Futsal World Cups and the Beach Soccer World Cups were excluded because of the different setting and rules of these games. 
Table 1 Injury surveillance in the Fédération Internationale de Football Association (FIFA) tournaments

\begin{tabular}{|c|c|c|c|c|c|c|c|c|c|c|c|c|c|c|c|}
\hline Tournament/year & 1998 & 1999 & 2000 & 2001 & 2002 & 2003 & 2004 & 2005 & 2006 & 2007 & 2008 & 2009 & 2010 & 2011 & 2012 \\
\hline \multicolumn{16}{|c|}{ FIFA Women's World Cups } \\
\hline World Cup & & $x$ & & & & $\mathrm{x}$ & & & & $\mathrm{x}$ & & & & $x$ & \\
\hline U19/U20 & & & & & $x$ & & $x$ & & $x$ & & $x$ & & $x$ & & $x$ \\
\hline U17 & & & & & & & & & & & $x$ & & $x$ & & $x$ \\
\hline \multicolumn{16}{|l|}{ FIFA Men's World Cups } \\
\hline World Cup & $\mathrm{x}$ & & & & $\mathrm{x}$ & & & & $\mathrm{x}$ & & & & $x$ & & \\
\hline U20 & & $x$ & & $x$ & & $x$ & & $x$ & & $x$ & & $x$ & & $x$ & \\
\hline U17 & & $x$ & & $x$ & & $x$ & & $x$ & & $x$ & & $x$ & & $x$ & \\
\hline Confederations Cup & & $x$ & & $x$ & & $x$ & & $x$ & & & & $x$ & & & \\
\hline Club World Cup & & & $x$ & & & & & $x$ & $x$ & $x$ & $x$ & $x$ & $x$ & $x$ & $x$ \\
\hline Futsal & & & $x$ & & & & $x$ & & & & $x$ & & & & $x$ \\
\hline Beach soccer & & & & & & & & & & & $x$ & & & $\mathrm{x}$ & \\
\hline
\end{tabular}

The incidence of injury was expressed as the number of injuries per match and the number of injuries per 1000 player-hours. The total player exposure hours were computed as: 11 players per team $\times 1.5 \mathrm{~h} \times$ number of returned team injury report forms. ${ }^{1}{ }^{25}$ And $95 \%$ CI for incidence rates was calculated as the incidence \pm 1.96 times the incidence divided by the square root of the number of injuries. Data were processed using Excel and SPSS. Statistical methods applied were frequencies, cross-tabulations and $\chi^{2}$ tests. Significance was accepted at the 5\% level.

\section{RESULTS}

A total of 1681 matches were played in the 53 tournaments, equivalent to 55473 player-hours. The team physicians completed and returned 3091 injury report forms, covering 51001.5 player-hours, to the FIFA Medical Officers. The average response rate was $92 \%$ (table 2).

A total of 3944 injuries were reported from 1546 matches, which is equivalent to an incidence of 77.3 injuries per 1000 player-hours (95\% CI 74.9 to 79.7$)$ or 2.6 injuries per match (95\% CI 2.5 to 2.7 ). The injury rate varied between 1.9 (FIFA Women's World Cups) and 3 (FIFA U20 World Cups) injuries per match in the different types of tournaments. The incidence was lower in tournaments for female players compared with the respective tournaments for male players, except for the Olympic Games.

Most injuries affected the lower extremity $(n=2706,70 \%)$, followed by injuries to the head and neck $(n=577,15 \%)$, trunk $(n=302,8 \%)$ and upper extremity $(n=269,7 \%)$. In almost all types of tournaments, the ankle $(n=718,19 \%)$, lower leg $(\mathrm{n}=615,16 \%)$ and head/neck were the predominantly injured body parts. Head/neck injuries were significantly more frequent in female than in male players $(17 \%$ vs $14 \%$ of injuries; $\left.\chi^{2}=9.3, \mathrm{p}<0.002\right)$.

Most injuries were diagnosed as contusions $(n=2090,55 \%)$, sprains $(n=580,15 \%)$ and strains/muscle fibre ruptures $(n=379$, $10 \%)$. In total, 81 injuries were diagnosed as concussion, 59 as ligament rupture and 63 as fracture (table 3). Female players incurred significantly more concussions than their male counterparts $\left(\chi^{2}=6.9, p<0.009\right)$. In Club World Cups, the percentage of contusions was lower and the percentages of fractures, ligament ruptures and strains were higher than in other tournaments for male players. This corresponds to the observation that more injuries in Club World Cups resulted in (a longer) absence from football (see below).
Most injuries were sustained during contact with another player, while $20 \%$ of all injuries were due to non-contact activities (722 of 3544). Almost half (47\%) of the contact injuries (1183 of 2501) were caused by foul play based on the judgement of the team physician. In tournaments of female players, significantly less contact injuries were caused by foul play compared with the respective tournament of male players, except for the FIFA U19/U20 World Cups. In Club World Cups, injuries were more frequently incurred without contact $(42 \%$ vs $\left.18 \% ; \chi^{2}=36.9, \mathrm{p}<0.0001\right)$ than in other tournaments for male players.

Information in relation to time-loss from sport, after injury, was available for 3307 (84\%) injuries in 1424 matches, since duration of time-loss was not documented in four tournaments (table 2). Almost half of the injuries $(n=1540,47 \%)$ were expected to prevent the player from participating in a match or training. The incidence of time-loss injuries was highest (1.5 per match) in the FIFA World Cups and lowest ( 0.7 per match) in the FIFA U17 Women's World Cups. The average incidence was 32.8 time-loss injuries per 1000 player-hours (95\% CI 31.1 to 34.5) or 1.1 per match (95\% CI 1.0 to 1.2$)$. The incidence of time-loss injuries was similar in male and female players when the same types of tournaments were compared, except for the FIFA World Cup where the injury rate was significantly lower in female players.

A total of $1225(37 \%)$ injuries were expected to prevent players from participating in a match or training for up to 1 week, a further $152(5 \%)$ for 8-28 days, and 61 (2\%) for more than 29 days. The expected duration of absence was not specified for 102 injuries. Injuries seemed to be more severe in the FIFA World Cups and the Club World Cups, and less severe in the FIFA U17 Women's World Cups than in other tournaments. On average, 1-1.5 severe injuries per tournament were reported, except for the FIFA World Cups with three per tournament and for the FIFA Confederations Cups with one severe injury in five tournaments.

The trend of the injury incidence over time in different tournaments of male and female players is shown in figures 1 and 2 . For male players (figure 1), the average number of injuries per match decreased in the FIFA World Cups (1998: 2.40, 95\% CI 2.01 to $2.79 ; 2010$ : $2.02,95 \%$ CI 1.67 to 2.37 ) and in the football tournaments of the Olympic Games (2000: 3.74, 95\% CI 3.06 to 4.42 ; 2012: $1.80,95 \%$ CI 1.40 to 2.20 ) from 1998 to 2012. For female players (figure 2), the contrary trend was 
Table 2 Number of tournaments, matches, returned forms, injuries and time-loss injuries and incidence of injuries in different types of top-level football tournaments $1998-2012$

\begin{tabular}{|c|c|c|c|c|c|c|c|c|c|c|}
\hline & \multicolumn{4}{|l|}{ Women } & \multicolumn{6}{|l|}{ Men } \\
\hline & $\begin{array}{l}\text { FIFA } \\
\text { World } \\
\text { Cups }\end{array}$ & Olympic Games & $\begin{array}{l}\text { FIFA } \\
\text { U19/U20 } \\
\text { World Cups }\end{array}$ & $\begin{array}{l}\text { FIFA } \\
\text { U17 } \\
\text { World Cups }\end{array}$ & $\begin{array}{l}\text { FIFA } \\
\text { World } \\
\text { Cups }\end{array}$ & Olympic Games & $\begin{array}{l}\text { FIFA } \\
\text { U20 } \\
\text { World Cups }\end{array}$ & $\begin{array}{l}\text { FIFA } \\
\text { U17 } \\
\text { World Cups }\end{array}$ & $\begin{array}{l}\text { FIFA } \\
\text { Confederations } \\
\text { Cups }\end{array}$ & $\begin{array}{l}\text { FIFA } \\
\text { Club } \\
\text { World Cups }\end{array}$ \\
\hline Tournaments & 4 & 4 & 6 & 3 & 4 & 4 & 7 & 7 & 5 & 9 \\
\hline Matches & 128 & 88 & 180 & 96 & 256 & 128 & 364 & 284 & 80 & 77 \\
\hline Returned forms & 235 & 169 & 258 & 192 & 504 & 251 & 662 & 553 & 131 & 136 \\
\hline Response rate (\%) & 92 & 96 & 99 & 100 & 98 & 98 & 91 & 97 & 82 & 88 \\
\hline All injuries & 228 & 208 & 455 & 225 & 590 & 291 & 991 & 680 & 132 & 144 \\
\hline Injuries per match $(95 \% \mathrm{Cl})$ & 1.9 (1.7 to 2.2$)$ & 2.5 (2.2 to 2.8 ) & 2.6 (2.4 to 2.8 ) & 2.3 (2.0 to 2.6 ) & 2.3 (2.1 to 2.5$)$ & $2.3(2.0$ to 2.6$)$ & $3.0(2.8$ to 3.2$)$ & 2.5 (2.3 to 2.7$)$ & 2.8 (2.3 to 3.3 ) & 2.1 (1.8 to 2.4$)$ \\
\hline Duration of time loss & $\mathrm{N}=181$ * & $\mathrm{N}=206$ & $\mathrm{~N}=397$ & $\mathrm{~N}=203$ & $\mathrm{~N}=417^{*}$ & $N=277$ & $\mathrm{~N}=767^{*}$ & $\mathrm{~N}=605$ & $\mathrm{~N}=116^{*}$ & $\mathrm{~N}=138$ \\
\hline 0 days & $86(48 \%)$ & $115(56 \%)$ & $233(58 \%)$ & $135(67 \%)$ & $131(31 \%)$ & $146(53 \%)$ & $453(60 \%)$ & $346(57 \%)$ & $65(57 \%)$ & $57(42 \%)$ \\
\hline $1-7$ days & $69(38 \%)$ & $63(31 \%)$ & $138(34 \%)$ & $48(24 \%)$ & $216(52 \%)$ & $108(39 \%)$ & $275(36 \%)$ & $215(36 \%)$ & $44(38 \%)$ & $49(36 \%)$ \\
\hline $8-29$ days & $8(4 \%)$ & $9(4 \%)$ & $17(4 \%)$ & $1(0.5 \%)$ & $44(11 \%)$ & $9(3 \%)$ & $20(3 \%)$ & $18(3 \%)$ & $6(5 \%)$ & $20(15 \%)$ \\
\hline$\geq 30$ days & $4(2 \%)$ & $3(1.5 \%)$ & $8(2 \%)$ & $2(1 \%)$ & $12(3 \%)$ & $6(2 \%)$ & $9(1 \%)$ & $6(1 \%)$ & $1(1 \%)$ & \\
\hline Not specified & $14(8 \%)$ & $16(8 \%)$ & $1(0.2 \%)$ & $17(8 \%)$ & $14(3 \%)$ & $8(3 \%)$ & $10(1 \%)$ & $20(3 \%)$ & 0 & $2(1.5 \%)$ \\
\hline Time-loss injuries & $95^{*}$ & 81 & 175 & 68 & $286^{*}$ & 132 & $314^{*}$ & 259 & $51^{*}$ & 81 \\
\hline Time-loss injuries per match (Cl 95\%) & $1.0 *(0.8-1.2)$ & $1.0(0.8-1.2)$ & $1.0(0.9-1.2)$ & $0.7(0.5-0.9)$ & $1.5^{*}(1.3-1.7)$ & $1.1(0.9-1.3)$ & $1.0 *(0.9-1.1)$ & $0.9(0.8-1.0)$ & $0.9 *(0.7-1.2)$ & $1.2(0.9-1.5)$ \\
\hline
\end{tabular}

${ }^{*}$ No information on time-loss documented in one tournament (1998/1999).

FIFA, the Fédération Internationale de Football Association. 
Table 3 Location, type and mechanism of injury in different top-level football tournaments

\begin{tabular}{|c|c|c|c|c|c|c|c|c|c|c|}
\hline & \multicolumn{4}{|l|}{ Women } & \multicolumn{6}{|l|}{ Men } \\
\hline & $\begin{array}{l}\text { FIFA } \\
\text { World } \\
\text { Cups }\end{array}$ & Olympic Games & $\begin{array}{l}\text { FIFA } \\
\text { U19/U20 } \\
\text { World Cups }\end{array}$ & $\begin{array}{l}\text { FIFA } \\
\text { U17 } \\
\text { World Cups }\end{array}$ & $\begin{array}{l}\text { FIFA } \\
\text { World } \\
\text { Cups }\end{array}$ & Olympic Games & $\begin{array}{l}\text { FIFA } \\
\text { U20 } \\
\text { World Cups }\end{array}$ & $\begin{array}{l}\text { FIFA } \\
\text { U17 } \\
\text { World Cups }\end{array}$ & $\begin{array}{l}\text { FIFA } \\
\text { Confederations } \\
\text { Cups }\end{array}$ & $\begin{array}{l}\text { FIFA } \\
\text { Club } \\
\text { World Cups }\end{array}$ \\
\hline Location & $\mathrm{N}=220$ & $\mathrm{~N}=208$ & $\mathrm{~N}=447$ & $\mathrm{~N}=223$ & $\mathrm{~N}=543$ & $\mathrm{~N}=290$ & $\mathrm{~N}=975$ & $\mathrm{~N}=674$ & $\mathrm{~N}=130$ & $\mathrm{~N}=144$ \\
\hline Head/neck & $48(21 \%)$ & $36(17 \%)$ & $74(17 \%)$ & $33(15 \%)$ & $67(12 \%)$ & $50(17 \%)$ & $152(15 \%)$ & $80(12 \%)$ & $21(16 \%)$ & $16(11 \%)$ \\
\hline Upper extremity & $22(10 \%)$ & $20(9 \%)$ & $34(8 \%)$ & $13(6 \%)$ & $41(8 \%)$ & $17(6 \%)$ & $63(6 \%)$ & $43(6 \%)$ & $7(5 \%)$ & $9(6 \%)$ \\
\hline Trunk & $15(7 \%)$ & $15(7 \%)$ & $51(12 \%)$ & $19(9 \%)$ & $38(7 \%)$ & $24(8 \%)$ & $73(7 \%)$ & $49(7 \%)$ & $8(6 \%)$ & $10(7 \%)$ \\
\hline Hip/groin & $3(1 \%)$ & $5(2 \%)$ & $12(3 \%)$ & $7(3 \%)$ & $24(4 \%)$ & $13(4 \%)$ & $44(4 \%)$ & $17(3 \%)$ & $6(5 \%)$ & $5(3 \%)$ \\
\hline Thigh & $22(10 \%)$ & $30(14 \%)$ & $39(9 \%)$ & $15(7 \%)$ & $108(20 \%)$ & $46(16 \%)$ & $126(13 \%)$ & $89(13 \%)$ & $20(15 \%)$ & $22(15 \%)$ \\
\hline Knee & $30(13 \%)$ & $23(11 \%)$ & $57(13 \%)$ & $28(13 \%)$ & $72(13 \%)$ & $39(13 \%)$ & $112(11 \%)$ & $74(11 \%)$ & $11(8 \%)$ & $26(18 \%)$ \\
\hline Lower leg & $33(15 \%)$ & $26(12 \%)$ & $56(13 \%)$ & $46(21 \%)$ & $84(15 \%)$ & $48(17 \%)$ & $155(16 \%)$ & $126(19 \%)$ & $20(15 \%)$ & $21(15 \%)$ \\
\hline Ankle & $34(15 \%)$ & $46(22 \%)$ & $104(24 \%)$ & $39(17 \%)$ & $77(14 \%)$ & $36(12 \%)$ & $184(19 \%)$ & $148(22 \%)$ & $26(20 \%)$ & $24(17 \%)$ \\
\hline Foot, toe & $13(6 \%)$ & $7(3 \%)$ & $20(4 \%)$ & $23(10 \%)$ & $32(6 \%)$ & $17(6 \%)$ & $66(7 \%)$ & $48(7 \%)$ & $11(8 \%)$ & $11(8 \%)$ \\
\hline Type & $\mathrm{N}=222$ & $\mathrm{~N}=202$ & $\mathrm{~N}=446$ & $\mathrm{~N}=219$ & $\mathrm{~N}=521$ & $\mathrm{~N}=288$ & $\mathrm{~N}=976$ & $\mathrm{~N}=673$ & $\mathrm{~N}=129$ & $\mathrm{~N}=141$ \\
\hline Concussion & $7(3 \%)$ & $11(5 \%)$ & $10(2 \%)$ & $5(2 \%)$ & $7(1 \%)$ & $2(1 \%)$ & $24(2 \%)$ & $11(2 \%)$ & $2(2 \%)$ & $2(1 \%)$ \\
\hline Fracture & $9(4 \%)$ & $3(1 \%)$ & $8(2 \%)$ & $3(1 \%)$ & $10(2 \%)$ & $5(2 \%)$ & $14(1 \%)$ & $3(<1 \%)$ & $2(2 \%)$ & $6(4 \%)$ \\
\hline Rupture of tendon or ligament & $7(3 \%)$ & $3(1 \%)$ & $9(2 \%)$ & $4(2 \%)$ & $9(2 \%)$ & $1(1 \%)$ & $9(1 \%)$ & $12(1 \%)$ & $1(1 \%)$ & $4(3 \%)$ \\
\hline Sprain & $35(16 \%)$ & $52(25 \%)$ & $96(22 \%)$ & $43(20 \%)$ & $73(14 \%)$ & $43(15 \%)$ & $107(11 \%)$ & $89(13 \%)$ & $20(16 \%)$ & $22(16 \%)$ \\
\hline Strain & $20(9 \%)$ & $17(8 \%)$ & $25(6 \%)$ & $23(11 \%)$ & $95(18 \%)$ & $21(7 \%)$ & $84(8 \%)$ & $49(7 \%)$ & $18(14 \%)$ & $27(19 \%)$ \\
\hline Contusion & $108(50 \%)$ & $93(46 \%)$ & $242(57 \%)$ & $116(53 \%)$ & $245(47 \%)$ & $167(58 \%)$ & $604(61 \%)$ & $390(58 \%)$ & $65(50 \%)$ & $60(43 \%)$ \\
\hline Skin lesion & $18(8 \%)$ & $6(3 \%)$ & $19(4 \%)$ & $5(2 \%)$ & $33(6 \%)$ & $30(10 \%)$ & $49(5 \%)$ & $29(4 \%)$ & $8(6 \%)$ & $9(6 \%)$ \\
\hline Others & $20(9 \%)$ & $16(7 \%)$ & $26(6 \%)$ & $20(9 \%)$ & $49(9 \%)$ & $20(7 \%)$ & $88(9 \%)$ & $86(13 \%)$ & $13(10 \%)$ & $11(8 \%)$ \\
\hline \multicolumn{11}{|l|}{ Mechanism } \\
\hline Non-contact & 39 of $224^{*}(17 \%)$ & 50 of $204(25 \%)$ & 58 of $446(13 \%)$ & 54 of $217(25 \%)$ & 125 of $430^{*}(29 \%)$ & 52 of $274(19 \%)$ & 150 of $868^{*}(17 \%)$ & 125 of $654(19 \%)$ & 22 of $114(19 \%)$ & 47 of $113(42 \%)$ \\
\hline Contact & 185 of $224^{*}(83 \%)$ & 154 of $204(75 \%)$ & 338 of $446(87 \%)$ & 163 of $217(75 \%)$ & 305 of $430^{*}(71 \%)$ & 222 of $274(81 \%)$ & 718 of $868^{*}(83 \%)$ & 519 of $654(81 \%)$ & 92 of $114(81 \%)$ & 66 of $113(58 \%)$ \\
\hline Foul of contact & 54 of $156^{*}(35 \%)$ & 39 of $107^{*}(36 \%)$ & 165 of $355(46 \%)$ & 47 of $161(29 \%)$ & 135 of $287^{*}(47 \%)$ & 114 of $181^{*}(63 \%)$ & 347 of $678^{*}(51 \%)$ & 227 of $454^{*}(50 \%)$ & 32 of $65^{*}(49 \%)$ & 23 of $57(40 \%)$ \\
\hline
\end{tabular}

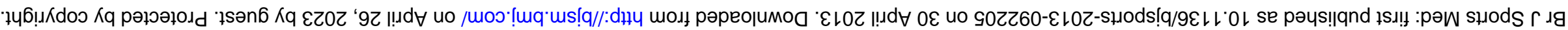




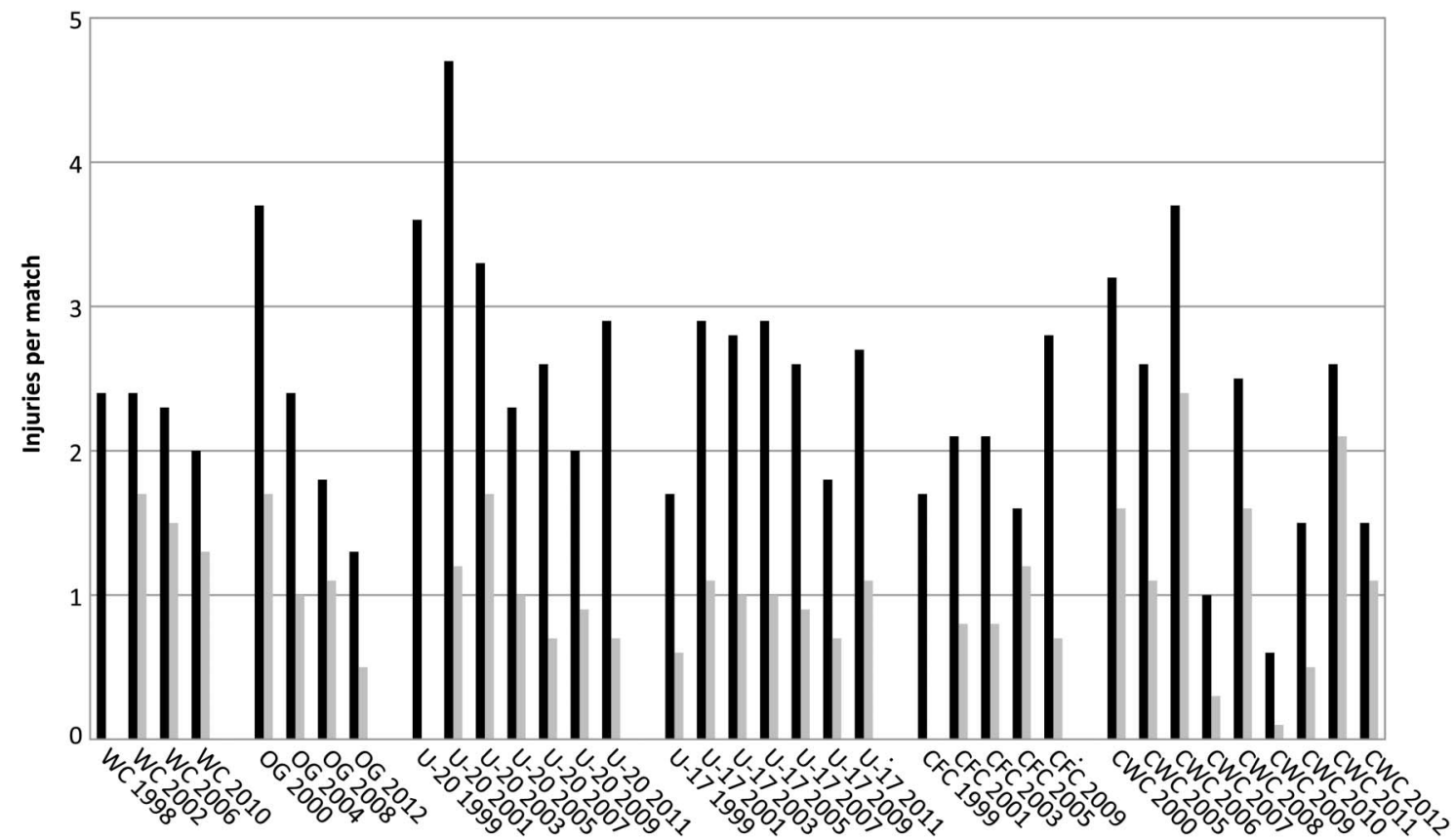

Figure 1 Injuries per match (black bars: all injuries; grey bars: time-loss injuries) in different top-level football tournaments of male players (WC, FIFA World Cup; OG, Olympic Games; U20, FIFA U20 World Cup; U17, FIFA U17 World Cup; CFC, FIFA Confederations Cup; CWC, Club World Cup).

observed in the FIFA Women's World Cups 1999 (1.28; 95\% CI 0.83 to 1.77$)$ to $2007(2.34 ; 95 \%$ CI 1.81 to 2.87$)$ and the Olympic Games 2000 (2.13; 95\% CI 1.39 to 2.87) to 2008 (2.88; 95\% CI 2.20 to 3.56). An analysis of the World Cup data with regard to the injury mechanism (figure 3 ) shows that these changes were mainly due to changes in the frequency of contact injuries while the incidence of non-contact injuries remained constant. For the incidence of time-loss injuries, similar trends as described above were observed but did not reach statistical significance due to the low number of cases, except for the FIFA U17 Women's World Cups 2008 (0.53; $95 \%$ CI 0.28 to 0.78$)$ to $2012(0.88$; $95 \%$ CI 0.55 to 1.21$)$. No obvious trend over time was observed in other types of tournaments.

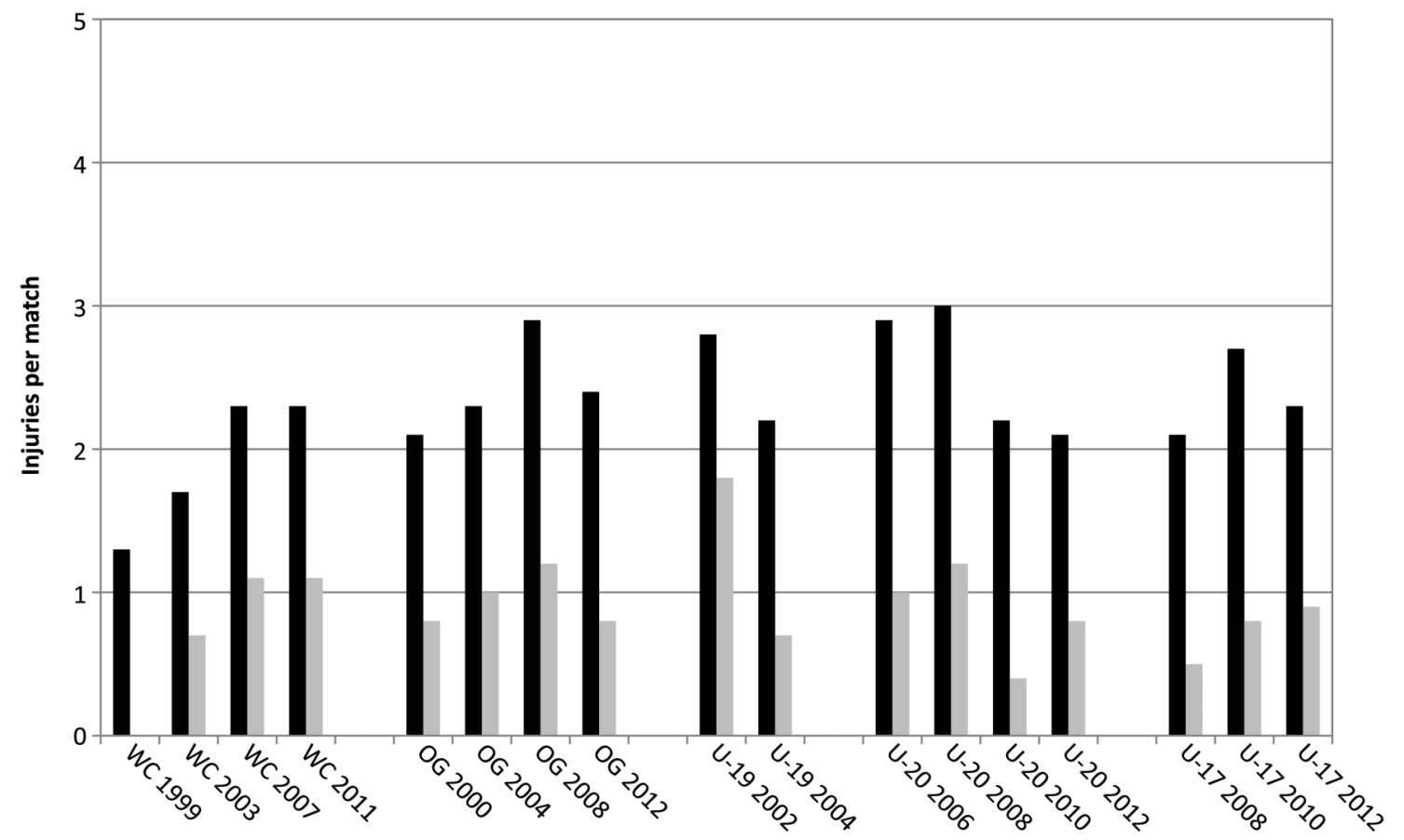

Figure 2 Injuries per match (black bars: all injuries; grey bars: time-loss injuries) in different top-level football tournaments of female players (WC, FIFA Women's World Cup; OG, Olympic Games; U19, FIFA U19 Women's World Cup; U20, FIFA U20 Women's World Cup; U17, FIFA U17 Women's World Cup). 


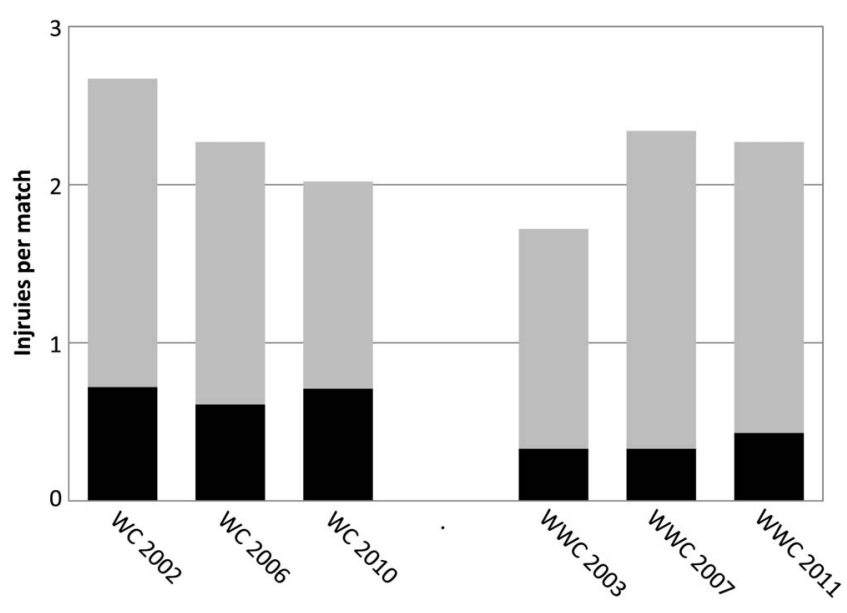

Figure 3 Injuries per match (dark grey, non-contact; light grey, contact) in the FIFA World Cups for male and female players (WC, FIFA World Cup; WWC, FIFA Women's World Cup) with regard to injury mechanism.

\section{DISCUSSION}

This present study is a survey on the incidence and characteristics of football injuries during all the 53 outdoor tournaments of FIFA and IOC over a period of 14 years. Data from 22 tournaments have been described previously in seven different publications, ${ }^{1} 11 \quad 12$ 20-22 24 while the injury data of 31 tournaments have not been published before. The FIFA Futsal World Cups have not been included in the present summary and were published separately, ${ }^{23}$ because of the differences in Laws of the Games. The methodology applied in the present study is well established, and the strengths and weaknesses have been discussed previously. ${ }^{1} 122426$

The average incidence of time-loss injuries $(32.8$ per 1000 player-hours, range 21.5-36.1) was within the range reported from the European championships ${ }^{16} 17$ and substantially higher than in the Asian tournaments. ${ }^{18}$ However, while in the FIFA World Cups and the Olympic Games only one to two severe injuries per tournament were reported, the number was twelve in EURO 2004, ${ }^{17}$ three in WOCO 2005, ${ }^{17} 13$ in EURO $2008,{ }^{16}$ five in the U21 EURO $2006^{16}$ and four in the U19 EURO 2007. ${ }^{16}$ The discrepancy might be caused by different

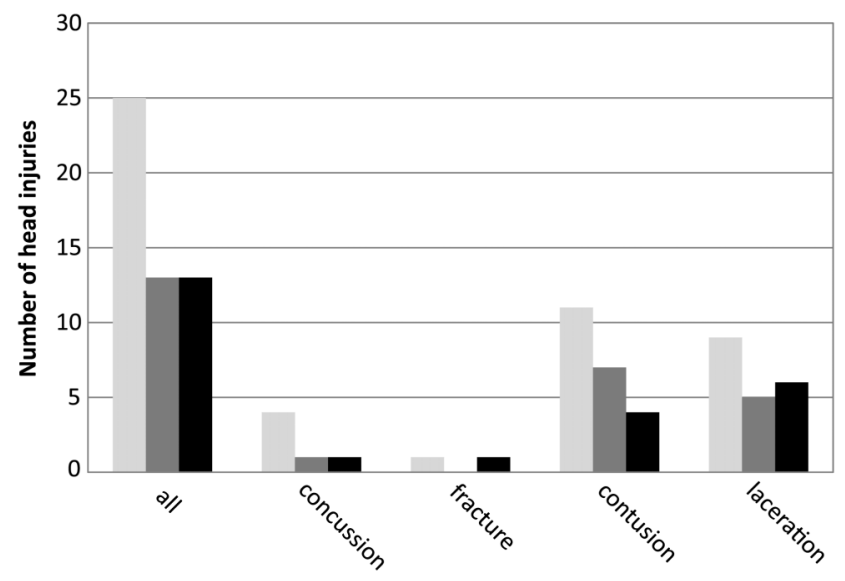

Figure 4 Number of head injuries in the Fédération Internationale de Football Association (FIFA) World Cups 2002 (black bars), 2006 (dark grey bars) and 2010 (light grey bars). data collection procedures. While in the FIFA injury surveillance system an estimate of the duration of absence due to injury should be reported by the team physicians immediately after the match, ${ }^{1}$ in the UEFA system (which includes time-loss injury only) all injuries were followed until the final day of rehabilitation even if this was after the tournament. ${ }^{16} 27$ Thus, it is possible that the rate of severe injury was underestimated in the present study. However, the incidence of fractures and concussions was higher in the present study than in the UEFA Championships 2006 to $2008 .{ }^{16}$ The severity of head injuries is not always obvious; therefore, a careful examination of players with a trauma to the head is highly recommended, and diagnosis and treatment should follow the recently published guidelines. ${ }^{28}$ The number of ligament ruptures could not be compared owing to the different categories for the type of injury in the FIFA and the UEFA injury surveillance systems.

The incidence of time-loss injuries was highest in the FIFA World Cups and lowest in the FIFA U17 Women's World Cups. The injury rates of male and female players were similar when the same types of tournaments were compared, except for the FIFA World Cups. In the FIFA World Cups, the incidence of injuries was significantly lower in female than in male players, as also reported previously for other tournaments. ${ }^{1} 16 \quad 22$ A decrease in the incidence of injuries was observed in the men's World Cups and Olympic Games during the period 1998-2012, and an opposite trend was seen in the respective women's tournaments (see figures 1 and 2). For the World Cups, it could be shown that the contrary trends for men and women were due to the changes in the number of contact injuries. One explanation for the decrease in contact injuries of male players is stricter refereeing. An impressive feature seen was the reduction in the number of head injuries by half after the International Football Association Board gave referees the authority to severely sanction what were felt to be injurious fouls such as intentional elbows to the head. ${ }^{21}$ This effect was reported for the 2006 FIFA World Cup, which remained stable also in the subsequent World Cups (figure 4). In women's tournaments, the playing style seems to have become more physical, as indicated by the increase in contact injuries, at least in the FIFA Women's World Cups (figure 3), and the refereeing less strict as can be concluded from the decrease in the issue of yellow cards from 2004 to 2010 (figure 5).

A trend towards an increasing injury rate from the World Cups, over the Olympic Games to the U19/U20 World Cups reported previously for men's and women's tournaments, ${ }^{22}$ could not be observed in the present study. On the contrary, not only the incidence of time-loss injuries but also the proportion of moderate/severe injuries was highest in the World Cups and the Club World Cups. The high number of matches played by these top-level players has been previously discussed as a potential risk factor for injury. ${ }^{29}$

\section{CONCLUSION}

The injury rates in the various types of FIFA World Cups had different trends over the past 14 years. These changes might have been influenced by the playing style, refereeing, extent and intensity of match play. Strict application of the Laws of the Games is an important means of injury prevention. More detailed studies (eg, on injury mechanism, refereeing in injury situations or the number of matches played) are needed to make specific recommendations for injury prevention in top-level tournaments. 
Figure 5 Average number of yellow cards per match for female football players in the Fédération Internationale de Football Association (FIFA) tournament and the Olympic Games (data from http://www.FIFA.com).

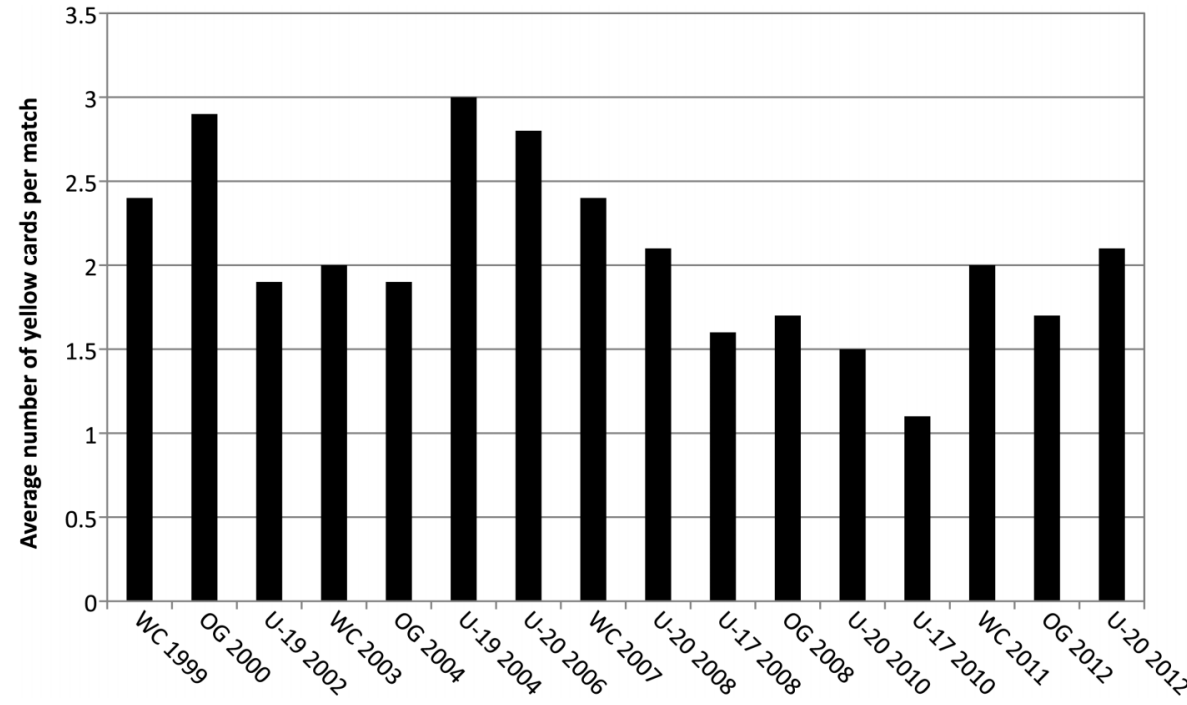

\section{What are the new findings?}

- On average, the incidence of time-loss injuries was highest in the FIFA World Cups and lowest in the FIFA U17 Women's World Cups.

- The incidence of time-loss injuries was similar in male and female players when the same types of tournaments were compared, except for the FIFA World Cup.

- The incidence of injuries in male players decreased in the FIFA World Cups and in the football tournaments of the Olympic Games from 1998 to 2012. The opposite trend was observed for female players in the FIFA Women's World Cups 1999 to 2007, the football tournaments of the Olympic Games 2000 to 2008, and the FIFA U17 Women's World Cups 2008 to 2012.

- Changes in the injury rates might have been influenced by the playing style and refereeing.
How might it impact on clinical practice in the near future?

- Strict application of the Laws of the Games and Fair Play are important aspects of injury prevention in top-level international football tournaments.

- Referees should be educated on their influence on injury rates.

- Decreasing the number of matches played, especially for the FIFA World Cup and the FIFA Club World Cup players, might contribute to a reduction in injury rates.

- More research is needed on risk factors for non-contact injuries, especially in the FIFA World Cup and the FIFA Club World Cup players.

Acknowledgements The authors highly appreciate the cooperation of the members of the FIFA Medical Committee (Chairman: Dr Michel D'Hooghe) and all team physicians who volunteered their time to collect data for this project. We thank Richard Charles, Sonja Schlumpf, Anja König, Monika Keller and Dr Katharina
Grimm for their assistance with data collection, and Dave O'Riordan for his assistance with data entry. The authors gratefully acknowledge the Fédération Internationale de Football Association (FIFA) for the funding of this study.

Contributors JD and AJ developed the study conception, design and methods. JD coordinated to data collection. AJ conducted the data analyses and wrote the manuscript. JD reviewed the manuscript and approved the final draft of the manuscript.

Funding The study was fully funded by the Fédération Internationale de Football Association (FIFA).

\section{Competing interests None.}

Ethics approval University of Zurich, Switzerland.

Provenance and peer review Not commissioned; externally peer reviewed.

Open Access This is an Open Access article distributed in accordance with the Creative Commons Attribution Non Commercial (CC BY-NC 3.0) license, which permits others to distribute, remix, adapt, build upon this work non-commercially, and license their derivative works on different terms, provided the original work is properly cited and the use is non-commercial. See: http://creativecommons.org/ licenses/by-nc/3.0/

\section{REFERENCES}

1 Junge A, Dvorak J, Graf-Baumann T, et al. Football injuries during FIFA tournaments and the Olympic Games, 1998-2001: development and implementation of an injury-reporting system. Am J Sports Med 2004;32(1 Suppl):80S-9S

2 Alonso JM, Edouard P, Fischetto $G$, et al. Determination of future prevention strategies in elite track and field: analysis of Daegu 2011 IAAF Championships injuries and illnesses surveillance. Br J Sports Med 2012;46:505-14.

3 Alonso JM, Junge A, Renstrom $P$, et al. Sports injuries surveillance during the 2007 IAAF World Athletics Championships. Clin J Sport Med 2009;19:26-32.

4 Alonso JM, Tscholl PM, Engebretsen $L$, et al. Occurrence of injuries and illnesses during the 2009 IAAF World Athletics Championships. Br J Sports Med 2010;44:1100-5.

5 Bahr R, Reeser JC. Injuries among world-class professional beach volleyball players. The Federation Internationale de Volleyball beach volleyball injury study. Am J Sports Med 2003:31:119-25.

6 Best JP, McIntosh AS, Savage TN. Rugby World Cup 2003 injury surveillance project. Br J Sports Med 2005;39:812-17.

7 Engebretsen L, Steffen K, Alonso JM, et al. Sports injuries and illnesses during the Winter Olympic Games 2010. Br J Sports Med 2010;44:772-80.

8 Fuller CW, Laborde F, Leather RJ, et al. International Rugby Board Rugby World Cup 2007 injury surveillance study. Br J Sports Med 2008;42:452-9.

9 Fuller CW, Molloy MG, Bagate $C$, et al. Consensus statement on injury definitions and data collection procedures for studies of injuries in rugby union. $\mathrm{Br}$ J Sports Med 2007:41:328-31.

10 Fuller CW, Sheerin K, Targett S. Rugby World Cup 2011: International Rugby Board Injury Surveillance Study. Br J Sports Med 2012. Published Online First: 9 June 2012 bjsports-2012-091155.

11 Junge A, Engebretsen L, Mountjoy ML, et al. Sports injuries during the Summer Olympic Games 2008. Am J Sports Med 2009;37:2165-72. 
12 Junge $A$, Langevoort $G$, Pipe $A$, et al. Injuries in team sport tournaments during the 2004 Olympic Games. Am J Sports Med 2006;34:565-76.

13 King DA, Gabbett TJ, Dreyer $C$, et al. Incidence of injuries in the New Zealand national rugby league sevens tournament. J Sci Med Sport 2006;9:110-18.

14 Langevoort G, Myklebust G, Dvorak J, et al. Handball injuries during major international tournaments. Scand J Med Sci Sports 2007;17:400-7.

15 Mountjoy M, Junge A, Alonso JM, et al. Sports injuries and illnesses in the 2009 FINA World Championships (Aquatics). Br J Sports Med 2010;44:522-7.

16 Hagglund $M$, Walden $M$, Ekstrand J. UEFA injury study-an injury audit of European Championships 2006 to 2008. Br J Sports Med 2009:43:483-9.

17 Walden $\mathrm{M}$, Hagglund M, Ekstrand J. Football injuries during European Championships 2004-2005. Knee Surg Sports Traumatol Arthrosc 2007:15:1155-62.

18 Yoon YS, Chai M, Shin DW. Football injuries at Asian tournaments. Am J Sports Med 2004;32(1 Suppl):36S-42S.

19 Van Mechelen W, Hlobil H, Kemper HC. Incidence, severity, aetiology and prevention of sports injuries. A review of concepts. Sports Med 1992;14:82-99.

20 Dvorak J, Junge $A$, Derman $W$, et al. Injuries and illnesses of football players during the 2010 FIFA World Cup. Br J Sports Med 2011;45:626-30.

21 Dvorak J, Junge A, Grimm K, et al. Medical report from the 2006 FIFA World Cup Germany. Br J Sports Med 2007:41:578-81.
22 Junge $A$, Dvorak J. Injuries in female football players in top-level international tournaments. Br J Sports Med 2007;41(Suppl 1):i3-7.

23 Junge A, Dvorak J. Injury risk of playing football in Futsal World Cups. Br J Sports Med 2010;44:1089-92.

24 Junge A, Dvorak J, Graf-Baumann T. Football injuries during the World Cup 2002. Am J Sports Med 2004;32(1 Suppl):23S-7S.

25 Fuller CW, Ekstrand J, Junge $A$, et al. Consensus statement on injury definitions and data collection procedures in studies of football (soccer) injuries. Br J Sports Med 2006;40:193-201.

26 Junge A, Engebretsen L, Alonso JM, et al. Injury surveillance in multi-sport events: the International Olympic Committee approach. Br J Sports Med 2008:42:413-21.

27 Hagglund M, Walden M, Bahr R, et al. Methods for epidemiological study of injuries to professional football players: developing the UEFA model. $\mathrm{Br} J$ Sports Med 2005:39:340-6.

28 McCrory P, Meeuwisse W, Johnston K, et al. Consensus statement on concussion in sport: the 3rd International Conference on Concussion in Sport held in Zurich, November 2008. Br J Sports Med 2009;43(Suppl 1):i76-90.

29 Ekstrand J, Walden M, Hagglund M. Football calendar and the wellbeing of players: correlation between match exposure of European footballers before the World Cup 2002 and their injuries and performances during that World Cup. Br J Sports Med 2004;38:493-7. 